\title{
Nutrition therapy in critical illness: a review of the literature for clinicians
}

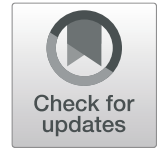

Kate J. Lambell ${ }^{1,2,3^{*}} \mathbb{D}$, Oana A. Tatucu-Babet ${ }^{1}$, Lee-anne Chapple ${ }^{4,5}$, Dashiell Gantner ${ }^{1,6}$ and Emma J. Ridley ${ }^{1,2}$

\begin{abstract}
Nutrition therapy during critical illness has been a focus of recent research, with a rapid increase in publications accompanied by two updated international clinical guidelines. However, the translation of evidence into practice is challenging due to the continually evolving, often conflicting trial findings and guideline recommendations. This narrative review aims to provide a comprehensive synthesis and interpretation of the adult critical care nutrition literature, with a particular focus on continuing practice gaps and areas with new data, to assist clinicians in making practical, yet evidence-based decisions regarding nutrition management during the different stages of critical illness.
\end{abstract}

Keywords: Critical illness, Intensive care, Nutrition therapy, Enteral nutrition, Parenteral nutrition

\section{Background}

In recent years, there has been much interest in the role of nutrition therapy in critical illness with an increase in publications and two updated international clinical guidelines [1, 2]. However, trial findings and guideline recommendations continue to be conflicting, making the translation of evidence into practice challenging. Further, it is becoming evident that the stage of critical illness and individual factors such as body composition may be important when considering how individuals might respond to nutrition interventions $[3,4]$. This narrative review aims to provide a summary and interpretation of the adult critical care nutrition literature, with a particular focus on continuing practice gaps and areas with new data, to help clinicians make practical, yet evidencebased decisions regarding nutrition management during critical illness.

\section{The metabolic response to critical illness and the role of nutrition therapy}

It is recognised that 'one-size fits all' and 'set and forget' approaches to nutrition do not adequately address the complex metabolic, hormonal, and immunological

\footnotetext{
* Correspondence: kate.lambell@monash.edu

${ }^{1}$ Australian and New Zealand Intensive Care Research Centre, School of

Public Health and Preventive Medicine, Monash University, Level 3, 555 St

Kilda Rd, Melbourne, VIC 3004, Australia

${ }^{2}$ Nutrition Department, Alfred Health, Melbourne, Australia

Full list of author information is available at the end of the article
}

changes that occur with critical illness $[3,5]$. It is essential that clinicians understand these processes and the impact on nutrient metabolism [4]. In 1942, Cuthbertson described two distinct metabolic phases during acute illness - the 'ebb' or early shock phase, followed by the 'flow' or catabolic phase [6]. In brief, the 'ebb' phase is characterised by haemodynamic instability and hormonal changes (including insulin resistance) in order to prioritise the delivery of energy substrates to vital tissues $[6,7]$. This survival mechanism results in endogenous glucose production as well as lower energy expenditure compared to pre-injury [4]. The 'flow' phase involves the breakdown of tissue (including lean muscle tissue) in order to provide substrates to cover the immediate needs for the 'fight or flight' response and to reduce the risk of bleeding and infection [4]. More recently, a third, anabolic recovery phase has been described [3]. It is during this recovery phase when resynthesis of lost tissue can take place and the body may be more metabolically able to process delivered nutrients $[3,4]$. Currently, there is no known clinical marker to identify when an individual shifts from one phase of critical illness to another. For the purposes of this review which aims to provide practical recommendations, we have adapted the terminology from the 2019 European Society of Parenteral and Enteral Nutrition (ESPEN) critical care guideline to describe the different stages of critical illness:

(c) The Author(s). 2020 Open Access This article is distributed under the terms of the Creative Commons Attribution 4.0 International License (http://creativecommons.org/licenses/by/4.0/), which permits unrestricted use, distribution, and reproduction in any medium, provided you give appropriate credit to the original author(s) and the source, provide a link to the Creative Commons license, and indicate if changes were made. The Creative Commons Public Domain Dedication waiver (http://creativecommons.org/publicdomain/zero/1.0/) applies to the data made available in this article, unless otherwise stated. 
ICU day 1-2 (acute early phase), ICU day 3-7 (acute late phase), and after ICU day 7 (recovery phase) [2].

While it is considered that nutrition may be more physiologically available and hence more important in the later phase of illness, due to the average intensive care unit (ICU) length of stay (LOS), the majority of nutrition trials have provided nutrition interventions in the acute phases of illness (regardless of the intended trial intervention period). Traditionally, it was thought that aggressive nutrition in the early stages of critical illness may improve clinical outcomes. However, evidence from recent randomised controlled trials (RCTs) does not support this, finding no benefit or harm with early nutrition delivery [8-11]. An explanation for this may be because a substantial amount of energy was provided in a period of critical illness where energy expenditure is decreased and endogenous production is enhanced [4]. Specifically, harm was observed in The Early Parenteral Nutrition Completing Enteral Nutrition in Adult Critically ill Patients (EPaNIC) trial, the largest nutrition trial in critical illness [10]. In a study of 4640 mixed ICU patients $(n=2818(61 \%)$ cardiac surgery patients) who were eligible to receive EN, late initiation of PN (started on day 8 of the ICU stay) led to an increase in the proportion of patients discharged alive and earlier from ICU and hospital (hazard ratio (HR) 1.06; 95\% CI 1.00-1.13; $p=0.04$ for both) when compared to PN commenced within $48 \mathrm{~h}$ of ICU admission [10]. Late initiation PN also led to a reduction in infectious complications $(22.8 \%$ vs $26.2 \%, p=0.008)$, cholestasis, duration of mechanical ventilation (MV), duration of renal replacement therapy, and health care costs [10]. Most recently, results from the largest enteral nutrition (EN) trial, The Augmented versus Routine approach to Giving Energy Trial (TARGET), support the theory that augmented energy delivery in the early phase of illness does not improve clinical outcomes compared to standard care [8]. This pragmatic prospective RCT of 3957 patients assessed 90-day mortality with augmented energy delivery (based on a predictive estimate of $1 \mathrm{ml} / \mathrm{kg}$ ideal body weight for height per day), compared to routine care [8]. Energy delivery was 50\% higher in the intervention group ( $30 \mathrm{kcal} / \mathrm{kg}$ ideal body weight/day) over the median 6-day nutrition delivery period (and approximated clinician estimated energy aims) but did not impact mortality or any secondary clinical outcomes [8]. However, it must be noted this study included a very 'general' (or unselected) population and that overfeeding may have occurred. Further post hoc work may increase the understanding and clinical implications of these results. Lack of benefit has also been observed with hypocaloric (low energy and adequate protein) and trophic (low energy and protein) feeding strategies compared to standard care, also provided early in critical illness and for short periods $[9,12]$. The results of these trials support the hypothesis that for mixed ICU patients, nutrition interventions in the acute early and acute late phase of critical illness may not impact clinical outcomes and may cause harm in some groups. Therefore, less than $100 \%$ of energy expenditure should be targeted in this period due to endogenous glucose production. It remains unknown whether nutrition interventions continued for longer, impact functional recovery and quality of life [3].

\section{Guidelines for nutrition therapy in critical illness}

There are currently four international clinical practice guidelines available to inform the nutrition management of critically ill patients $[1,2,13,14]$. Table 1 summarises each guideline and outlines key recommendations and their level of supporting evidence.

\section{Energy in critical illness}

Determination of energy requirements is one of the most significant challenges in critical illness and is of vital importance as prescribed targets are used to guide nutrition delivery. Predictive equations that estimate energy expenditure are the most commonly used method due to their ease of application but are often inaccurate compared to measured energy expenditure using indirect calorimetry [15]. Table 2 summarises why predictive equation estimates vary from measured energy expenditure $[16,17]$. Importantly, inaccuracies increase at the extremes of weight, in the most severely unwell, and in older and more malnourished populations [16, 18]. Despite these failings, predictive equations continue to be widely used and are recommended in international clinical guidelines in the absence of indirect calorimetry $[1,2]$.

\section{Estimating energy expenditure via $\mathrm{VO}_{2}$ and $\mathrm{VCO}_{2}$}

Due to the persistent inaccuracies associated with the use of predictive equations, other methods (many of which have existed for some time) have been recently recommended in the 2019 ESPEN critical care guideline in the absence of indirect calorimetry [2]. Resting energy expenditure (REE) can be estimated via $\mathrm{VCO}_{2}$ (carbon dioxide production) from the ventilator and the rewritten Weir formula $\left(\mathrm{REE}=\mathrm{VCO}_{2} \times 8.19\right)$ or using $\mathrm{VO}_{2}$ (oxygen consumption) from a pulmonary artery catheter via the Fick method [19-22]. A recent study in 84 critically ill patients reported a higher level of agreement between energy requirements estimated by the $\mathrm{VCO}_{2}$ method and measured REE compared to other predictive equations [20]. There are methodological limitations to note with this method: an assumed normal respiratory quotient (RQ) of 0.85 is used, which is the RQ of most nutritional products (with $\mathrm{RQ}=\mathrm{VCO}_{2} / \mathrm{VO}_{2}$, normally ranging between 


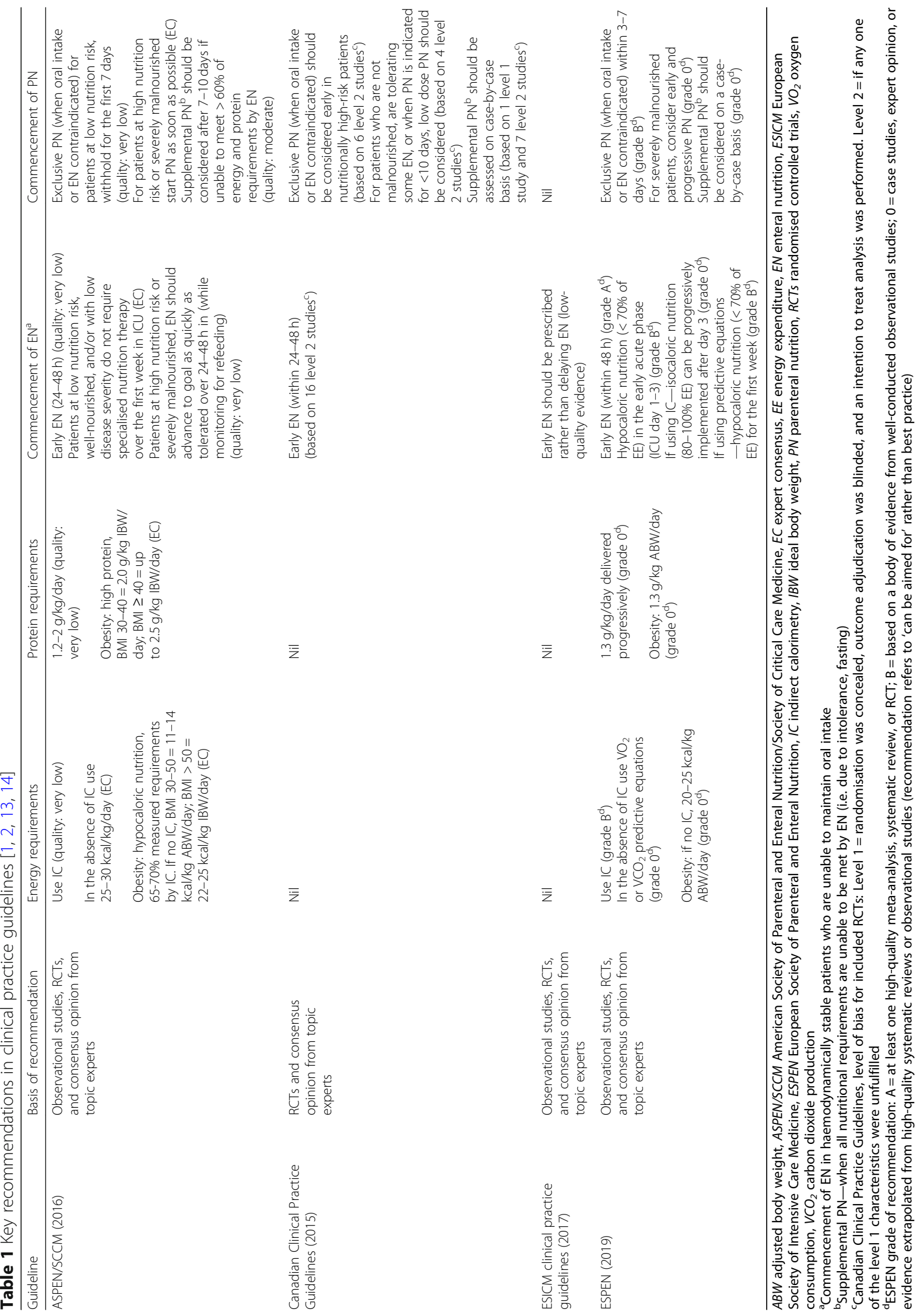


Table 2 Reasons equations for predicting energy expenditure lead to inaccurate results compared to measured energy expenditure $[16,17]$

\begin{tabular}{ll}
\hline Equation factors & Patient and system factors \\
\hline - Sample size of the original equation & - Individual patient heterogeneity in the metabolic response to critical illness \\
- The characteristics of the original development population & - Differing body composition (fat-free mass and fat mass) \\
(including age, body composition, and disease state) & $\begin{aligned} \text { - Changes in medical management over time in elements that impact } \\
\text { - The population characteristics in which the equation is used }\end{aligned}$ \\
- The addition of commonly used 'injury' or 'stress' factors & \\
- Using an adjusted body weight with the equation & \\
\hline
\end{tabular}

0.67 and 1.2 depending on the proportion of carbohydrate, fat, and protein being combusted) [23]. However, in critical illness, RQ may also be influenced by endogenous glucose production and by periods of hypo- and hyper-ventilation, and is likely to fluctuate between populations $[19,20]$.

\section{Measuring energy expenditure in the critically ill-indirect calorimetry}

Indirect calorimetry allows for the measurement of $\mathrm{VO}_{2}$ and $\mathrm{VCO}_{2}$ through the ventilator and is the gold standard method for measuring REE in critical illness when ideal test conditions are implemented [24]. Both the European (ESPEN) and American (ASPEN/SCCM) clinical practice guidelines recommend the use of indirect calorimetry to measure energy expenditure (Table 1) $[1,2]$.

Despite the guideline recommendations, only three single-centre RCTs have investigated the impact of delivering energy according to a measured energy expenditure (via indirect calorimetry) compared to energy delivery using a $25-\mathrm{kcal} / \mathrm{kg} /$ day estimate (standard care) on clinical outcomes. The first, published in 2011, included 130 patients and observed a trend towards reduced hospital mortality (primary outcome) in the intervention group using intention to treat (ITT) analysis $(n=21 / 65,32.3 \%$, vs $31 / 65,47.7 \%, p=0.058)$ [25]. However, infectious complications $(n=37$ vs $20, p=0.05)$ and mean ( \pm standard deviation) duration of $\mathrm{MV}$ $(16.1 \pm 14.7$ vs $10.5 \pm 8.3$ days, $p=0.03)$ and ICU LOS $(17.2 \pm 14.6$ vs $11.7 \pm 8.4$ days, $p=0.04)$ were increased in the intervention group compared to standard care [25]. In a more recent and slightly larger trial of 203 patients, no differences were observed in the primary outcome (self-reported physical component summary score of SF36 at 6 months) between intervention and control in the ITT analysis ( $n=199,22.9$ vs $23.0, p=0.99$, respectively) or in any clinically important secondary outcomes [11]. However, in a post hoc analysis, a longer median (interquartile range) ICU LOS was observed in the intervention group $(8(5-25)$ vs $7(4-12)$ days, $p=0.03)$ [11]. Lastly, in a pilot study $(n=40)$, no statistically significant differences were observed between groups in the primary outcome of change in bioelectrical impedance phase angle (related to nutritional status and prognosis) from baseline to ICU discharge [26]. However, a declining trend in mean phase angle was observed in the standard care group $\left(3.31 \pm 1.34^{\circ}\right.$ to $2.95 \pm 1.15^{\circ}, p=$ 0.077 ), and a significantly shorter ICU LOS was reported in the intervention versus the standard care group (13 \pm 8 vs $24 \pm 20$ days, $p<0.05$ ) [26].

Consistently across all three RCTs, indirect calorimetry was feasible and energy targets were more closely met when using indirect calorimetry in place of fixedenergy prescription. Methodological characteristics must be noted in interpreting these results; all studies were unblinded and single-centre in design and were likely underpowered to demonstrate true differences in clinical and functional recovery outcomes. Further, these studies aimed to meet $100 \%$ of indirect calorimetry targets early in the ICU admission, which recent evidence suggests is not beneficial, and there was limited investigation into high-risk subgroups in which indirect calorimetry may have avoided harm by under- or overfeeding (i.e. obesity). Despite this, these studies do not suggest that indirect calorimetry to guide energy delivery is superior to using predictive equations with regard to improving clinical outcomes.

\section{Measurement or estimation of energy expenditure?}

Regardless if energy expenditure is measured or estimated, there is no consensus on how much energy should be provided. Based on current evidence, the most significant benefit of using indirect calorimetry is to personalise energy prescription and avoid under- or overdelivery of energy across the different phases of critical illness. For this reason, it is the opinion of the authors that if indirect calorimetry is available, it should be used primarily in patients where the clinicians are concerned about under- or overestimating energy needs (i.e. obese and underweight individuals) [27]. When used, clinicians should aim for high-quality tests by reaching a steady test state (defined as a variation in $\mathrm{VO}_{2}$ and $\mathrm{VCO}_{2}$ less than $10 \%$ over five consecutive minutes), conduct tests for $\geq 30 \mathrm{~min}$, and repeat tests at least weekly (or more frequently if clinically indicated) [24].

For the majority of clinicians, current practice will continue to include the use of a predictive equation for estimation of energy needs. Clinicians must be aware that accurate estimation of energy expenditure with a predictive equation requires considerable knowledge of 
the underlying patient condition, the factors that alter the metabolic response to illness, and the limitations of the equation being used. It is also important to consider that delivery of calories to meet measured or estimated energy expenditure may not equate to what should be provided to improve outcomes. This may be particularly relevant in the acute early phase of critical illness where endogenous substrate mobilisation provides a substantial portion of the energy requirement and insulin resistance occurs, and therefore, a conservative energy target should be the aim [28]. Energy prescription and energy delivery (including non-nutritional sources such as dextrose and propofol) should be regularly reviewed in the context of the patient's clinical condition and metabolic phase to prevent considerable under- or overfeeding [29].

\section{Protein in critical illness}

In states of stress, such as in critical illness, the synthesis of acute phase proteins and those involved in immune function increase to support recovery [30]. Rapid and significant loss of skeletal muscle mass occurs to provide precursor amino acids to aid this process [31]. Despite a lack of definitive evidence, clinical guidelines recommend protein delivery of between 1.2 and $2 \mathrm{~g} / \mathrm{kg} /$ day (Table 1) based on the assumption that like energy, delivery of adequate protein will attenuate skeletal muscle wasting and improve clinical outcomes. The ASPEN/ SCCM guidelines also make recommendations for higher protein provision in specific clinical conditions (i.e. burns, obesity, and multi-trauma), which again are based on limited, primarily observational data and expert opinion [1]. The variation in the clinical guideline recommendations for protein delivery reflects the lack of good quality trials investigating the role of protein provision on clinical outcomes.

\section{Protein delivery and clinical outcomes}

Higher protein provision has been associated with improved survival in a number of observational studies [32-36]. Conversely, higher protein delivery during ICU admission has led to increased urea production and has been associated with increased muscle wasting in a small observational study $[10,11,31,37]$.

In RCTs aiming to compare high versus lower protein delivery in critical illness, no benefit has been shown with an increased protein dose, although most have been underpowered to demonstrate an effect on clinical outcomes [11, 37-39]. The largest RCT $(n=474)$ investigating intravenous protein provided at a dose of up to 100 g/day compared to standard care found no impact on the primary outcome of renal dysfunction [37]. A smaller RCT compared intravenous protein at a dose of either $0.8 \mathrm{~g} / \mathrm{kg}(n=60)$ or $1.2 \mathrm{~g} / \mathrm{kg}(n=59)$ delivered over ten days while controlling for energy intake [38]. While there was no difference in the primary outcome of handgrip strength, the group who received the higher protein dose had less fatigue and higher forearm thickness (using ultrasound) at day 7 [38]. However, these findings may be impacted by unadjusted confounders and must be interpreted with caution [40].

Timing of protein delivery may also influence clinical outcomes. Two observational studies have reported increased survival with early increased protein delivery (day 3-4) [32, 33]. In the largest study $(n=2253)$, early protein delivery $(>0.7 \mathrm{~g} / \mathrm{kg} /$ day versus $\leq 0.7 \mathrm{~g} / \mathrm{kg} /$ day $)$ was associated with increased survival (adjusted HR $0.83,95 \%$ CI $0.71-0.97, p=0.017$ ) [33]. Contrary to these findings, in a post hoc secondary analysis of the EPaNIC trial, a cumulative protein dose, rather than the cumulative glucose dose, early during ICU stay was associated with delayed ICU discharge [41]. Further, a single-centre retrospective cohort study $(n=455)$ reported a lower protein intake $(<0.8 \mathrm{~g} / \mathrm{kg} /$ day $)$ before day 3 and high protein intake $(>0.8 \mathrm{~g} / \mathrm{kg} /$ day $)$ after day 3 was associated with lower 6-month mortality (adjusted HR 0.609; 95\% CI 0.480-0.772, $p<0.001$ ) compared to patients with overall high protein intake [42]. Prospective, randomised data is required to inform the most appropriate amount and timing of protein to deliver to critically ill patients. Adequately powered RCTs are urgently needed to better understand the impact of both protein dose and timing on clinical outcomes in critical illness. Such trials should ideally control for energy delivery, by ensuring it is consistent across both the intervention and control groups.

\section{How much energy and protein do patients get in clinical practice?}

One of the most important pieces of information that clinicians should consider is that patients do not receive the energy and protein dose that is prescribed. In a recent retrospective observational study of 17,524 patients, the mean \pm standard deviation energy and protein received was $56 \pm 30 \%$ and $52 \pm 30 \%$ of the intended aim, respectively [43]. This has consistently been shown across different time periods and geographical regions [44]. The reasons for this are multifactorial, including interruptions to EN for procedures, delayed initiation of nutrition, and gastrointestinal intolerance [45].

\section{What energy and protein targets should clinicians aim for?}

In light of the current evidence, the authors support the gradual introduction of nutrition therapy during the acute phases of critical illness, with energy and protein targets outlined in Fig. 1. In patients who are 'at risk' of refeeding syndrome, it is crucial that nutrition therapy is 


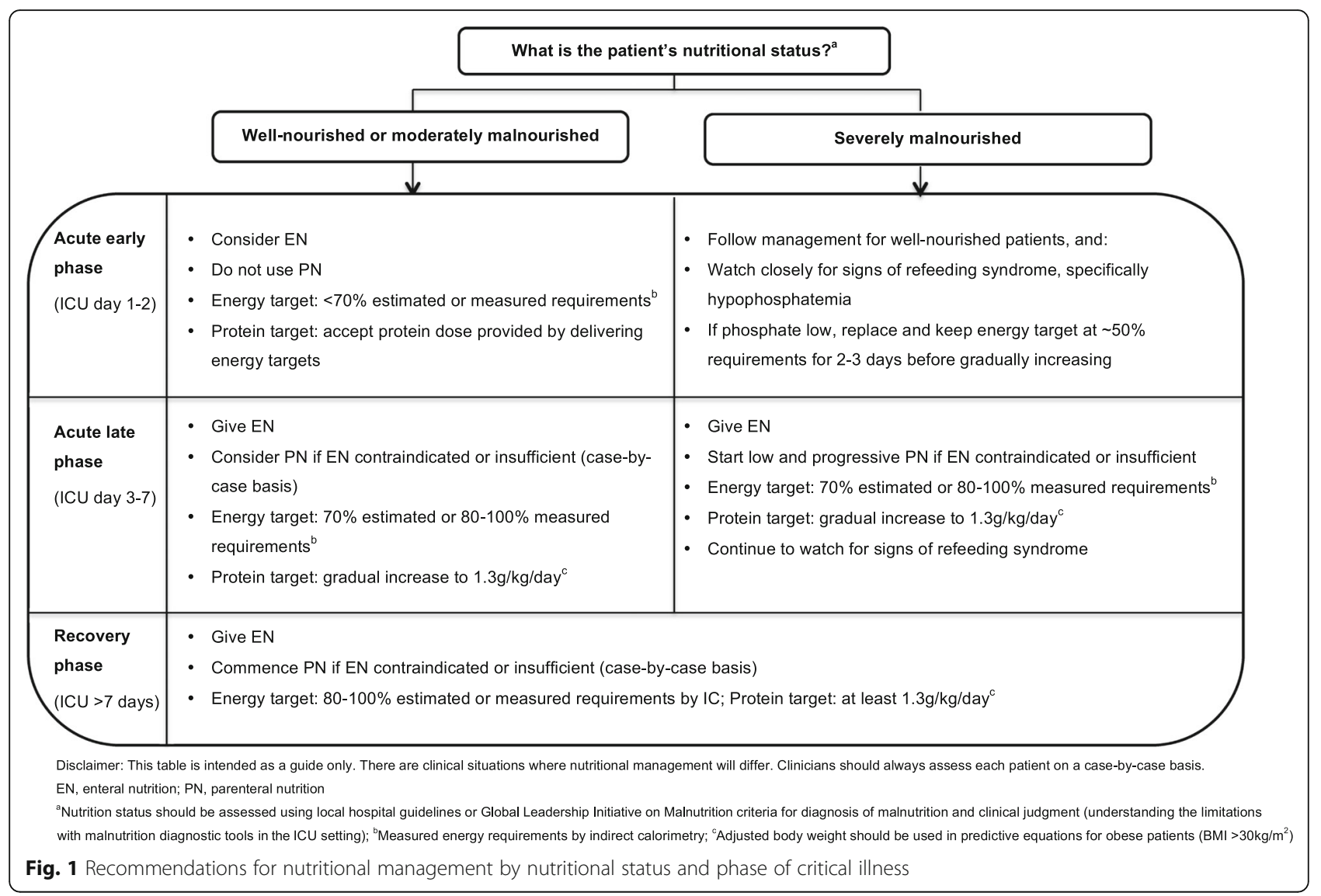

introduced slowly, and electrolytes are monitored closely and replaced as necessary [46]. If hypophosphatemia is present (e.g. $<0.65 \mathrm{mmol} / \mathrm{l}$ ) in the first few days after starting nutrition therapy, then energy delivery should be restricted to $\sim 50 \%$ requirements for $2-3$ days [47].

\section{Enteral nutrition}

\section{When to start?}

Early provision of EN (within $48 \mathrm{~h}$ of ICU admission) in patients who are mechanically ventilated is an established standard of care and supported by all clinical guidelines $[1,2,13,14]$.

\section{How should EN be delivered?}

The most common method of delivering EN in ICU is via a gastric tube, with a continuous hourly infusion. However, this continuous supply of nutrients does not mimic normal volitional intake which is most commonly in the form of boluses followed by periods of fasting. Recently, it has been proposed that bolus (intermittent) feeding may be more physiologic and therefore superior to continuous feeding [48]. A systematic review was conducted as part of the recent ESPEN guidelines to investigate whether bolus EN has an advantage over continuously administered EN [2]. Including 5 small prospective studies and 236 patients, a significant reduction in diarrhoea was observed with continuous versus bolus administration of EN (RR 0.42, 95\% CI 0.19-0.91, $p=0.03$ ) [2]. No differences in gastric residual volume, rates of aspiration, or pneumonia were observed. It has also been suggested that muscle protein synthesis may be improved when EN is delivered via a bolus when compared to continuous delivery, and a phase II multicentre RCT has recently completed recruitment to investigate this question (ClinicalTrials.gov NCT02358512) [5, 48]. Moving from continuous to bolus delivery of EN in the ICU is a significant change to practice in most countries, which would require a variation in feeding protocols and extensive education of clinical staff. Due to the considerable practice change associated, until definitive evidence is available to support one method of delivery over the other, it is reasonable that clinicians continue to deliver EN via a continuous infusion.

\section{EN delivery-an ongoing challenge}

International guidelines are unanimous in favouring EN delivery into the stomach or small bowel over parenteral nutrition (PN) $[1,2]$. Due to continued and consistent recommendations to meet energy requirements over many years, many strategies to 'optimise' EN delivery 
closer to predicted targets have been tested, including the use of evidence-based feeding protocols, small bowel feeding tubes, prokinetic drugs, and increase of the acceptable gastric residual volume [49-58]. Guideline recommendations to maximise $\mathrm{EN}$ delivery are summarised in Table 3. Despite the implementation of such interventions, these trials have observed modest to no increase in nutrition delivery and none have demonstrated a beneficial effect on clinical outcomes, potentially related to the disconnect between 'delivery' and 'utilisation' of nutrients.

\section{Parenteral nutrition}

\section{When to start?}

PN is indicated when the delivery of nutrients via the gastrointestinal tract is contraindicated or insufficient. $\mathrm{PN}$ can be provided either as a full source of nutrition (exclusive PN) or as an additional nutrition source when full requirements are not able to be met by oral intake or EN (supplemental PN). Recent RCT evidence has indicated there are no differences in clinical outcomes, including mortality and infective complications, when PN is provided versus EN in a modern day ICU setting and when energy provided is comparable in both groups $[59,60]$. Guideline recommendations for when to commence PN differ and are outlined in Table 1. Due to the potential harm with early $\mathrm{PN}$, it is the opinion of the authors that if oral intake or EN is contraindicated, then
PN should only be considered between ICU days 3 and 7 and that supplemental PN be considered on an individual case-by-case basis (Fig. 1).

\section{Body composition analysis}

The measurement of weight and muscularity is important in the assessment of nutrition status and monitoring the effectiveness of nutrition interventions [61]. However, due to the extreme fluid shifts that critically ill patients experience, measured weight and/or muscularity assessed by traditional bedside methods (e.g., subjective physical assessment, mid-arm muscle circumference) may be inaccurate in this patient population [62-64]. Table 4 summarises the emerging tools for assessment of muscularity in the ICU setting: computed tomography image analysis, bioimpedance analysis, and ultrasound. Currently, these methods for assessing muscle mass and quality are mostly limited to research [64-66]. There is an essential need to evaluate which bedside tools can accurately measure muscle mass, and identify those individuals with lower than normal muscularity, as well as to better understand the clinical importance of changes in muscle health and the interface with nutrition interventions in critical illness.

\section{Nutritional management in critically ill subgroups}

RCTs conducted to date have focused on key practice questions, but included heterogenic populations. These

Table 3 Guideline recommendations for strategies to improve EN delivery [1, 2, 13, 14]

\begin{tabular}{|c|c|c|c|c|}
\hline Strategy & $\begin{array}{l}\text { Evidenced-based feeding } \\
\text { protocol }\end{array}$ & $\begin{array}{l}\text { GRV (minimum } 500 \mathrm{ml} \\
\text { cut-off) }\end{array}$ & $\begin{array}{l}\text { Appropriate and timely use of } \\
\text { prokinetics for EN intolerance }\end{array}$ & $\begin{array}{l}\text { Post-pyloric tubes for EN } \\
\text { intolerance }\end{array}$ \\
\hline $\begin{array}{l}\text { ASPEN/SCCM } \\
(2016)\end{array}$ & $\begin{array}{l}\text { Use an EN protocol (designed } \\
\text { and implemented to increase } \\
\text { the overall percentage of goal } \\
\text { energy delivered) (quality: } \\
\text { moderate to high) }\end{array}$ & $\begin{array}{l}\text { Do not use GRVs as } \\
\text { part of routine care to } \\
\text { monitor ICU patients } \\
\text { on EN } \\
\text { If GRVs are used, use } \\
500 \mathrm{ml} \text { cut-off } \\
\text { (quality: low) }\end{array}$ & $\begin{array}{l}\text { Use metoclopramide or } \\
\text { erythromycin where } \\
\text { indicated (quality: low) }\end{array}$ & $\mathrm{Nil}$ \\
\hline $\begin{array}{l}\text { Canadian Clinical } \\
\text { Practice Guidelines } \\
(2015)\end{array}$ & $\begin{array}{l}\text { Use an EN protocol (that } \\
\text { details strategies to improve } \\
\text { delivery of EN) (based on } 2 \\
\text { level } 2 \text { studies and } 3 \text { cluster } \\
\text { RCTs }^{a} \text { ) }\end{array}$ & $\begin{array}{l}\text { Use GRV of } 250-500 \\
\text { ml every } 4-6 \text { h (based } \\
\text { on } 3 \text { level } 2 \text { studies }^{a} \text { ) }\end{array}$ & 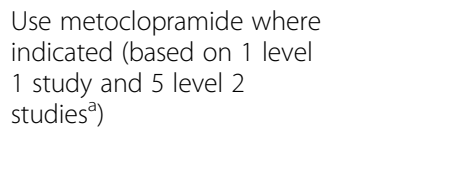 & 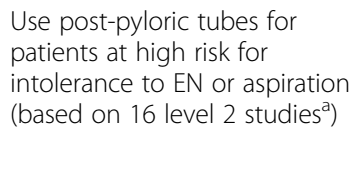 \\
\hline ESPEN (2019) & Nil & $\begin{array}{l}\text { EN should only be } \\
\text { delayed when GRV is } \\
>500 \mathrm{ml} / 6 \mathrm{~h}\left(\text { grade } 0^{\mathrm{b}} \text { ) }\right.\end{array}$ & $\begin{array}{l}\text { Use IV erythromycin as a first line } \\
\text { therapy (grade of recommendation } \mathrm{B}^{\mathrm{b}} \text { ) } \\
\text { or use IV metaclopramide or } \\
\text { combination therapy (grade } 0^{\mathrm{b}} \text { ) } \\
\text { Alternatively, combination } \\
\text { therapy (IV metoclopramide } \\
\text { and erythromycin) (grade } 0^{\mathrm{b}} \text { ) }\end{array}$ & $\begin{array}{l}\text { Use post-pyloric feeding for } \\
\text { EN intolerance not resolved } \\
\text { with prokinetics (grade } B^{b} \text { ) }\end{array}$ \\
\hline
\end{tabular}

ASPEN/SCCM American Society of Parenteral and Enteral Nutrition/Society of Critical Care Medicine, EC expert consensus, EN enteral nutrition, ESICM European Society of Intensive Care Medicine, ESPEN European Society of Parenteral and Enteral Nutrition, GRV gastric residual volume, ICU intensive care unit, IV intravenous therapy

${ }^{a}$ Canadian Clinical Practice Guidelines, level of bias for included RCTs: Level 1 = randomisation was concealed, outcome adjudication was blinded, and an intention to treat analysis was performed. Level $2=$ if any one of the forementioned characteristics was unfulfilled

${ }^{\mathrm{b}}$ ESPEN grade of recommendation: $\mathrm{A}=$ at least one high-quality meta-analysis, systematic review, or RCT; $\mathrm{B}=$ body of evidence from well-conducted observational studies; 0 = case studies, expert opinion, or evidence extrapolated from high-quality systematic reviews or observational studies (recommendation refers to 'can be aimed for' rather than best practice) 
Table 4 Methodologies for assessment of skeletal muscle in ICU [64-66]

\begin{tabular}{|c|c|c|c|c|}
\hline Method & Measurement & Details & Benefits & Limitations \\
\hline $\begin{array}{l}\mathrm{CT} \text { image } \\
\text { analysis at the } \\
\text { abdominal }(\mathrm{L} 3) \\
\text { area }\end{array}$ & $\begin{array}{l}\cdot \text { Muscle CSA } \\
\left(\mathrm{cm}^{2}\right) \\
\cdot \text { Muscle quality } \\
\text { (density) (Hounsfield } \\
\text { units) }\end{array}$ & $\begin{array}{l}\text { - Specialised software can be used to } \\
\text { measure muscle area and density using } \\
\text { a CT slice at L3 } \\
\text { - Quantification of muscle CSA at L3 is } \\
\text { highly correlated to whole body muscle } \\
\text { (using scans performed for clinical } \\
\text { purposes) }\end{array}$ & $\begin{array}{l}\text { - Provides specific and } \\
\text { precise results } \\
\text { - Published cut-off values } \\
\text { to identify patients with } \\
\text { lower than normal } \\
\text { muscularity }\end{array}$ & $\begin{array}{l}\text { - Limited for use in patients who } \\
\text { have had a CT at L3 area } \\
\text { - Specialist training and time } \\
\text { required for analysis }\end{array}$ \\
\hline $\begin{array}{l}\text { Bioimpedance } \\
\text { analysis (multi- } \\
\text { frequency or } \\
\text { spectroscopy) }\end{array}$ & $\begin{array}{l}\text { - Fat-free mass }(\mathrm{kg}) \\
\text { - Phase angle } \\
(50 \mathrm{kHz})\end{array}$ & $\begin{array}{l}\text { - Involves application of a weak current at } \\
\text { differing frequencies, through electrodes } \\
\text { placed on the hands and feet } \\
\text { - Total body water, percentage body fat, and } \\
\text { fat-free mass are estimated via regression } \\
\text { equations (with assumed constants for } \\
\text { estimating intra- and extracellular water) } \\
\text { - Raw data such as phase angle (which is } \\
\text { independent of weight and related to } \\
\text { cellular health) may be a predictor of } \\
\text { outcome in critically ill populations }\end{array}$ & $\begin{array}{l}\text { - Easy and quick to use } \\
\text { - Safe (no radiation } \\
\text { involved) }\end{array}$ & $\begin{array}{l}\text { - Fat-free mass estimates are not } \\
\text { likely to be reliable in critically ill } \\
\text { patients who experience signifi } \\
\text { cant fluid shifts } \\
\text { - Positioning (separation in limbs) } \\
\text { and electrode placement may be } \\
\text { challenging in some ICU patients }\end{array}$ \\
\hline Ultrasound & $\begin{array}{l}\text { - Muscle thickness } \\
(\mathrm{cm}) \\
\text { - Muscle CSA }\left(\mathrm{cm}^{2}\right) \\
\text { - Muscle quality } \\
\text { (echogenicity) }\end{array}$ & $\begin{array}{l}\text { - Muscle thickness and CSA can be } \\
\text { measured at different sites (i.e. quadriceps, } \\
\text { upper arm) } \\
\text { - Muscle quality can also be assessed using } \\
\text { specialist software }\end{array}$ & $\begin{array}{l}\text { - Readily available in } \\
\text { most ICUs } \\
\text { - Easy, safe, and quick to } \\
\text { use }\end{array}$ & $\begin{array}{l}\text { - No consensus on the ideal sites } \\
\text { to predict whole body muscle or } \\
\text { to monitor changes over time } \\
\text { - Role of oedema on measurements } \\
\text { is unclear } \\
\text { - No widely accepted cut-points } \\
\text { to identify patients with low } \\
\text { muscularity }\end{array}$ \\
\hline
\end{tabular}

CSA cross-sectional area, CT computed tomography, ICU intensive care unit, L3 third lumbar

studies have not shown clinical benefit with nutrition interventions for reasons previously discussed though there are several patient subgroups that may still benefit from nutrition interventions. In an attempt to investigate such groups, a number of large RCTs have included pre-planned subgroup analysis (e.g. response to the intervention according to differing BMI category). However, results from these types of analyses must be interpreted with caution as the sample size may be small. Moreover, if a benefit or harm is observed in a subgroup, but the overall trial result suggests no difference, it must be considered that another subgroup hidden in the heterogeneous population may have experienced the opposite effect.

\section{Malnourished}

The diagnosis of malnutrition in critically ill patients is challenging. Diagnostic tools, such as the widely used Subjective Global Assessment (SGA) and criteria outlined in the recent Global Leadership Initiative in Malnutrition (GLIM) recommendations, rely heavily on obtaining accurate anthropometrical data, weight and diet history, and the assessment of muscle mass, all of which are difficult to acquire in the acute early phase of ICU admission [61]. For this reason, RCT evidence attempting to investigate if patients who may be malnourished respond differently to nutrition is limited to subgroup analysis in patients with differing BMI categories or nutrition risk scores $[10,12,67]$. To date, no benefit has been observed when more or less nutrition is provided in these subgroups although the numbers included are often small. Further, BMI is a poor surrogate measure for malnutrition, and commonly used nutrition risk scores have not been well validated, which limits any conclusions on how nutrition therapy may affect outcomes in this vulnerable subgroup [2]. Despite the lack of evidence in this area, the authors support minimising progression of malnutrition. Where possible, clinicians should use local hospital guidelines or the recent GLIM criteria, combined with clinical judgement to diagnose malnutrition. As outlined in Fig. 1, in severely malnourished patients, we encourage early low dose nutrition therapy in the acute early phase, with a slow progression to target during the acute late phase, while carefully monitoring for refeeding syndrome.

\section{Obese}

The unique and complex care needs of obese patients $\left(B M I \geq 30 \mathrm{~kg} / \mathrm{m}^{2}\right)$ are amplified when they become critically ill and include a greater risk of insulin resistance and loss of lean muscle mass, and wide variations in macronutrient metabolism, which makes nutrition management complex $[4,68]$. There is currently very limited, low-quality evidence to inform nutrition provision in the critically ill obese patient, and as a result, the latest clinical guidelines provide inconsistent recommendations regarding energy and protein targets (Table 1). 
In the TARGET trial, 1423 obese critically ill patients were included, representing the largest population of obese patients in an ICU nutrition study [8]. While not statistically significant, the obese subgroup was the only pre-specified subgroup where the point estimate sat on the side of benefit with greater energy delivery [8]. These results require formal evaluation in a robust, adequately powered and blinded clinical trial; however, they highlight that obese patients may respond differently to nutrition delivery than non-obese individuals and that there is a critical need for further research in this patient group.

In the absence of definitive evidence of the impact on functional recovery in particular, it is the opinion of the authors that obese patients should be managed like any other patient admitted to the ICU. If predictive equation estimates are used, a method to adjust body weight should be used in the nutrition prescriptions (not actual weight), and delivery monitored carefully with the knowledge that most predictive equations significantly underestimate requirements in this group [69]. It may be appropriate to consider a weight loss regime in the recovery phase once the acute illness has resolved.

\section{The non-ventilated patient}

Critically ill patients who are not intubated may have prolonged periods of inadequate oral intake. In a prospective observational study, 50 patients who were not receiving any EN or PN were studied for 7 days following endotracheal extubation [70]. The average daily energy and protein intake failed to exceed $50 \%$ of daily requirements on all 7 days for the entire population [70]. To prevent malnutrition, it is important that clinicians monitor the oral intake of awake patients and the authors support the ESPEN guideline recommendation that medical nutrition therapy should be considered for all patients staying in the ICU for $>2$ days regardless of their ventilation status [2].

\section{Post-ICU}

The limited data available indicates that the predominant mode of nutrition following an ICU admission is via the oral route and nutrition intake in this period remains below clinician recommendations. In 32 patients from 2 centres, nutrition intake was assessed 3 times per week in the post-ICU phase [71]. Oral nutrition was the most common type of nutrition therapy (55\% of study days) [71]. The median [interquartile range] energy and protein intake was 79\% [41-108\%] and 73\% [44-98\%], respectively; however, considerable variation was observed depending on the type of nutrition therapy provided, with energy and protein provision the lowest in patients who received no additional oral nutrition supplements (37\% [21-66\%] of target energy and 48\% [13-63\%] protein) [71]. A second single-centre study of patients with traumatic brain injury indicated poorer intake postICU compared to in ICU, and nutritional deficit was significantly greater in patients who consumed oral nutrition alone compared to those receiving artificial nutrition support [72]. Despite this, dietitians spent just $20 \%$ of their time managing patients receiving oral nutrition therapy and saw the patients a mean of 2.2 (1.0) times per week for 34 (20) min per occasion on the post-ICU ward [72]. The predominant issues impacting nutrition intake are reported as appetite, disinterest in food, and taste changes [73].

Unfortunately, non-individualised, 'one-size fits all' processes to the management of nutrition are likely impacting on nutrition adequacy in the post-ICU period. In one of the only studies investigating processes that impact nutrition in the post-ICU period, it was found that of nine patients transferred to the post-ICU ward, six had their gastric tube removed on the advice of the medical team without assessment of nutrition intake [73]. Early removal of gastric tubes may improve patient comfort and is encouraged by many post-surgical protocols, but has the potential to negatively impact nutrition intake [73]. The decision to remove a tube should be made on a case-by-case basis and after consultation with the patient, the treating team, and the dietitian [74]. Among other possible causes, it is plausible that inadequate nutrition following critical illness may result in significant energy and protein deficit and may explain the lack of benefit in long-term outcomes observed in nutrition studies that have delivered an intervention in the acute early and late phases. This is an important knowledge gap for investigation and to provide initial insights; a multicentre RCT is underway (ClinicalTrials. gov NCT03292237).

\section{Conclusion}

Results from recent large-scale trials highlight that in heterogeneous groups of patients, full feeding in the acute phases of critical illness does not provide an advantage over trophic feeding and may be harmful. It remains uncertain what impact specific nutrition interventions have in the recovery phase of illness and in specific subgroups who may respond differently to nutrition interventions. The effect of nutrition delivery on other clinically meaningful outcomes, such as muscle health and physical function, is also insufficiently studied. We recommend nutrition prescriptions that tailor for pre-admission nutrition status, and severity and stage of illness. Particular attention should be paid to patients that are in (or likely to stay in) ICU for greater than a week, with ongoing monitoring of nutrition delivery and regular review of measured or estimated nutrition requirements. 


\section{Abbreviations}

ASPEN/SCCM: American Society of Parenteral and Enteral Nutrition/Society of Critical Care Medicine; EN: Enteral nutrition; ESPEN: European Society of Parenteral and Enteral Nutrition; ICU: Intensive care unit; PN: Parenteral nutrition; RCT: Randomised control trial

\section{Authors' contributions}

EJR conceived of the idea. KJL and EJR drafted the manuscript. All authors reviewed and commented on the manuscript and approved the final draft.

\section{Funding}

Not applicable.

\section{Availability of data and materials}

Not applicable.

\section{Ethics approval and consent to participate}

Not applicable.

\section{Consent for publication}

Not applicable.

\section{Competing interests}

EJR has received an honorarium and has unrestricted, investigator-initiated grant funding from Baxter Healthcare Corporation for trial Clinicaltrials.gov NCT03292237. The other authors declare that they have no competing interests.

\section{Author details}

${ }^{1}$ Australian and New Zealand Intensive Care Research Centre, School of Public Health and Preventive Medicine, Monash University, Level 3, 555 St Kilda Rd, Melbourne, VIC 3004, Australia. ${ }^{2}$ Nutrition Department, Alfred Health, Melbourne, Australia. ${ }^{3}$ Department of Dietetics, Nutrition and Sport, La Trobe University, Melbourne, Australia. ${ }^{4}$ Discipline of Acute Care Medicine, University of Adelaide, Adelaide, Australia. ${ }^{5}$ Intensive Care Research, Royal Adelaide Hospital, Adelaide, Australia. Intensive Care Unit, Alfred Health, Melbourne, Australia.

Received: 14 July 2019 Accepted: 14 January 2020

\section{Published online: 04 February 2020}

\section{References}

1. Taylor BE, McClave SA, Martindale RG, Warren MM, Johnson DR, Braunschweig C, et al. Guidelines for the provision and assessment of nutrition support therapy in the adult critically ill patient: Society of Critical Care Medicine (SCCM) and American Society for Parenteral and Enteral Nutrition (A.S.P.E.N.). Crit Care Med. 2016;44(2):390-438.

2. Singer $P$, Blaser AR, Berger MM, Alhazzani W, Calder PC, Casaer MP, et al. ESPEN guideline on clinical nutrition in the intensive care unit. Clin Nutr. 2019:38(1):48-79.

3. Wischmeyer PE. Tailoring nutrition therapy to illness and recovery. Crit Care. 2017;21(Suppl 3):316

4. Preiser J-C. The stress response of critical illness: metabolic and hormonal aspects. Switzerland: Springer Cham; 2016. [cited 2019 July 11]. Available from: http://ezproxy.lib.monash.edu.au/login?url=http://link.springer.com/1 0.1007/978-3-319-27687-8

5. Bear DE, Wandrag L, Merriweather JL, Connolly B, Hart N, Grocott MPW, et al. The role of nutritional support in the physical and functional recovery of critically ill patients: a narrative review. Crit Care. 2017:21(1):226.

6. Cuthbertson DP. Post-shock metabolic response. Lancet. 1942;239(6189):433-7.

7. Marik PE, Bellomo R. Stress hyperglycemia: an essential survival response! Crit Care. 2013;17(2):305.

8. Target Investigators ftACTG, Chapman M, Peake SL, Bellomo R, Davies A Deane $A$, et al. Energy-dense versus routine enteral nutrition in the critically ill. N Engl J Med. 2018;379(19):1823-34.

9. Rice TW, Wheeler AP, Thompson BT, Steingrub J, Hite RD, Moss M, et al. Initial trophic vs full enteral feeding in patients with acute lung injury: the EDEN randomized trial. JAMA. 2012;307(8):795-803.

10. Casaer MP, Mesotten D, Hermans G, Wouters PJ, Schetz M, Meyfroidt G, et al. Early versus late parenteral nutrition in critically ill adults. N Engl J Med. 2011;365(6):506-17.
11. Allingstrup MJ, Kondrup J, Wiis J, Claudius C, Pedersen UG, Hein-Rasmussen $\mathrm{R}$, et al. Early goal-directed nutrition versus standard of care in adult intensive care patients: the single-centre, randomised, outcome assessorblinded EAT-ICU trial. Intensive Care Med. 2017:43(11):1637-47.

12. Arabi YM, Aldawood AS, Haddad SH, Al-Dorzi HM, Tamim HM, Jones G, et al. Permissive underfeeding or standard enteral feeding in critically ill adults. N Engl J Med. 2015;372(25):2398-408

13. Reintam Blaser A, Starkopf J, Alhazzani W, Berger MM, Casaer MP, Deane $A M$, et al. Early enteral nutrition in critically ill patients: ESICM clinical practice guidelines. Intensive Care Med. 2017;43(3):380-98.

14. Critical Care Nutrition. The Canadian clinical practice guidelines (2015). Available from: http://www.criticalcarenutrition.com [Accessed 24 Jul 2019].

15. Tatucu-Babet OA, Ridley EJ, Tierney AC. Prevalence of underprescription or overprescription of energy needs in critically ill mechanically ventilated adults as determined by indirect calorimetry: a systematic literature review. JPEN J Parenter Enteral Nutr. 2016;40(2):212-25.

16. Frankenfield DC, Coleman A, Alam S, Cooney RN. Analysis of estimation methods for resting metabolic rate in critically ill adults. JPEN J Parenter Enteral Nutr. 2009:33(1):27-36.

17. Walker RN, Heuberger RA. Predictive equations for energy needs for the critically ill. Respir Care. 2009:54(4):509-21.

18. Reeves MM, Capra S. Predicting energy requirements in the clinical setting: are current methods evidence based? Nutr Rev. 2003;61(4):143-51.

19. Kagan I, Zusman O, Bendavid I, Theilla M, Cohen J, Singer P. Validation of carbon dioxide production (VCO2) as a tool to calculate resting energy expenditure (REE) in mechanically ventilated critically ill patients: a retrospective observational study. Crit Care. 2018;22(1):186.

20. Stapel SN, de Grooth HJ, Alimohamad H, Elbers PW, Girbes AR, Weijs PJ, et al. Ventilator-derived carbon dioxide production to assess energy expenditure in critically ill patients: proof of concept. Crit Care. 2015; 19:370

21. Flancbaum L, Choban PS, Sambucco S, Verducci J, Burge JC. Comparison of indirect calorimetry, the Fick method, and prediction equations in estimating the energy requirements of critically ill patients. Am J Clin Nutr. 1999;69(3):461-6.

22. Basile-Filho A, Martins MA, Marson F, Evora PRB. An easy way to estimate energy expenditure from hemodynamic data in septic patients. Acta Cirurgica Brasileira. 2008:23:112-7.

23. Gupta RD, Ramachandran R, Venkatesan P, Anoop S, Joseph M, Thomas N Indirect calorimetry: from bench to bedside. Indian J Endocrinol Metab. 2017;21(4):594-9.

24. McClave SA, Spain DA, Skolnick JL, Lowen CC, Kieber MJ, Wickerham PS, et al. Achievement of steady state optimizes results when performing indirect calorimetry. JPEN J Parenter Enteral Nutr. 2003;27(1):16-20.

25. Singer $P$, Anbar R, Cohen J, Shapiro H, Shalita-Chesner M, Lev S, et al. The tight calorie control study (TICACOS): a prospective, randomized, controlled pilot study of nutritional support in critically ill patients. Intensive Care Med. 2011;37(4):601-9.

26. Gonzalez-Granda A, Schollenberger A, Haap M, Riessen R, Bischoff SC. Optimization of nutrition therapy with the use of calorimetry to determine and control energy needs in mechanically ventilated critically ill patients: the ONCA study, a randomized, prospective pilot study. JPEN J Parenter Enteral Nutr. 2019:43(4):481-9.

27. Oshima T, Berger MM, De Waele E, Guttormsen AB, Heidegger CP, Hiesmayr $M$, et al. Indirect calorimetry in nutritional therapy. A position paper by the ICALIC study group. Clin Nutr. 2017;36(3):651-62.

28. Wernerman J, Christopher KB, Annane D, Casaer MP, Coopersmith CM, Deane AM, et al. Metabolic support in the critically ill: a consensus of 19. Crit Care. 2019;23(1):318

29. Charriere M, Ridley E, Hastings J, Bianchet O, Scheinkestel C, Berger MM Propofol sedation substantially increases the caloric and lipid intake in critically ill patients. Nutrition. 2017;42:64-8.

30. Wolfe RR. The underappreciated role of muscle in health and disease. Am J Clin Nutr. 2006;84(3):475-82

31. Puthucheary ZA, Rawal J, McPhail M, Connolly B, Ratnayake G, Chan P, et al. Acute skeletal muscle wasting in critical illness. JAMA. 2013; 310(15):1591-600

32. Weijs PJ, Looijaard WG, Beishuizen A, Girbes AR, Oudemans-van Straaten HM. Early high protein intake is associated with low mortality and energy overfeeding with high mortality in non-septic mechanically ventilated critically ill patients. Crit Care. 2014;18(6):701. 
33. Bendavid I, Zusman O, Kagan I, Theilla M, Cohen J, Singer P. Early administration of protein in critically ill patients: a retrospective cohort study. Nutrients. 2019;11(1):106

34. Allingstrup MJ, Esmailzadeh N, Wilkens Knudsen A, Espersen K, Hartvig Jensen $\mathrm{T}$, Wiis J, et al. Provision of protein and energy in relation to measured requirements in intensive care patients. Clin Nutr. 2012;31(4):462-8.

35. Compher C, Chittams J, Sammarco T, Nicolo M, Heyland DK. Greater protein and energy intake may be associated with improved mortality in higher risk critically ill patients: a multicenter, multinational observational study. Crit Care Med. 2017:45(2):156-63.

36. Nicolo M, Heyland DK, Chittams J, Sammarco T, Compher C. Clinical outcomes related to protein delivery in a critically ill population: a multicenter, multinational observation study. JPEN J Parenter Enteral Nutr. 2016;40(1):45-51.

37. Doig GS, Simpson F, Bellomo R, Heighes PT, Sweetman EA, Chesher D, et al. Intravenous amino acid therapy for kidney function in critically ill patients: a randomized controlled trial. Intensive Care Med. 2015;41 (7):1197-208.

38. Ferrie $\mathrm{S}$, Allman-Farinelli $\mathrm{M}$, Daley $\mathrm{M}$, Smith $\mathrm{K}$. Protein requirements in the critically ill: a randomized controlled trial using parenteral nutrition. JPEN J Parenter Enteral Nutr. 2016;40(6):795-805.

39. Fetterplace K, Deane AM, Tierney A, Beach L, Knight LD, Presneill J, et al. Targeted full energy and protein delivery in critically ill patients: a pilot randomized controlled trial (FEED trial). JPEN J Parenter Enteral Nutr. 2018;42(8):1252-62.

40. Casaer MP, Van den Berghe G. Comment on "protein requirements in the critically ill: a randomized controlled trial using parenteral nutrition". JPEN J Parenter Enteral Nutr. 2016;40(6):763.

41. Casaer MP, Wilmer A, Hermans G, Wouters PJ, Mesotten D, Van den Berghe G Role of disease and macronutrient dose in the randomized controlled EPaNIC trial: a post hoc analysis. Am J Respir Crit Care Med. 2013;187(3):247-55.

42. Koekkoek W, van Setten CHC, Olthof LE, Kars J, van Zanten ARH. Timing of PROTein INtake and clinical outcomes of adult critically ill patients on prolonged mechanical VENTilation: the PROTINVENT retrospective study. Clin Nutr. 2019;38(2):883-90

43. Ridley EJ, Peake SL, Jarvis M, Deane AM, Lange K, Davies AR, et al. Nutrition therapy in Australia and New Zealand intensive care units: an international comparison study. JPEN J Parenter Enteral Nutr. 2018;42(8):1349-57.

44. Cahill NE, Dhaliwal R, Day AG, Jiang X, Heyland DK. Nutrition therapy in the critical care setting: what is "best achievable" practice? An international multicenter observational study. Crit Care Med. 2010;38(2):395-401.

45. Passier RH, Davies AR, Ridley E, McClure J, Murphy D, Scheinkestel CD. Periprocedural cessation of nutrition in the intensive care unit: opportunities for improvement. Intensive Care Med. 2013;39(7):1221-6.

46. Mehanna HM, Moledina J, Travis J. Refeeding syndrome: what it is, and how to prevent and treat it. BMJ. 2008;336(7659):1495-8.

47. Doig GS, Simpson F, Heighes PT, Bellomo R, Chesher D, Caterson ID, et al. Restricted versus continued standard caloric intake during the management of refeeding syndrome in critically ill adults: a randomised, parallel-group, multicentre, single-blind controlled trial. Lancet Respir Med. 2015;3(12):943-52.

48. Patel JJ, Rosenthal MD, Heyland DK. Intermittent versus continuous feeding in critically ill adults. Curr Opin Clin Nutr Metab Care. 2018;21(2):116-20.

49. Doig GS, Simpson F, Finfer S, Delaney A, Davies AR, Mitchell I, et al. Effect of evidence-based feeding quidelines on mortality of critically ill adults: a cluster randomized controlled trial. JAMA. 2008;300(23):2731-41.

50. Heyland DK, Lemieux M, Shu L, Quisenberry K, Day AG. What is "best achievable" practice in implementing the enhanced protein-energy provision via the enteral route feeding protocol in intensive care units in the United States? Results of a multicenter, quality improvement collaborative. JPEN J Parenter Enteral Nutr. 2016;42(2):308-17.

51. Barr J, Hecht M, Flavin KE, Khorana A, Gould MK. Outcomes in critically ill patients before and after the implementation of an evidence-based nutritional management protocol. Chest. 2004;125(4):1446-57.

52. Heyland DK, Murch L, Cahill N, McCall M, Muscedere J, Stelfox HT, et al. Enhanced protein-energy provision via the enteral route feeding protocol in critically ill patients: results of a cluster randomized trial. Crit Care Med. 2013; 41(12):2743-53.

53. Martin CM, Doig GS, Heyland DK, Morrison T, Sibbald WJ, Southwestern Ontario Critical Care Research N. Multicentre, cluster-randomized clinical trial of algorithms for critical-care enteral and parenteral therapy (ACCEPT). CMAJ. 2004;170(2):197-204.

54. Montejo JC, Minambres E, Bordeje L, Mesejo A, Acosta J, Heras A, et al. Gastric residual volume during enteral nutrition in ICU patients: the REGANE study. Intensive Care Med. 2010;36(8):1386-93.
55. Reignier J, Mercier E, Le Gouge A, Boulain T, Desachy A, Bellec F, et al. Effect of not monitoring residual gastric volume on risk of ventilator-associated pneumonia in adults receiving mechanical ventilation and early enteral feeding: a randomized controlled trial. JAMA. 2013;309(3):249-56.

56. Poulard F, Dimet J, Martin-Lefevre L, Bontemps F, Fiancette M, Clementi E, et al. Impact of not measuring residual gastric volume in mechanically ventilated patients receiving early enteral feeding: a prospective before-after study. JPEN J Parenter Enteral Nutr. 2010;34(2):125-30.

57. Davies AR. Enteral nutrition in ICU: small bowel or stomach? And how much? Crit Care Resusc. 2012;14(2):99-100.

58. Nguyen NQ, Chapman MJ, Fraser RJ, Bryant LK, Holloway RH. Erythromycin is more effective than metoclopramide in the treatment of feed intolerance in critical illness. Crit Care Med. 2007;35(2):483-9.

59. Harvey SE, Parrott F, Harrison DA, Bear DE, Segaran E, Beale R, et al. Trial of the route of early nutritional support in critically ill adults. N Engl J Med. 2014;371(18):1673-84.

60. Reignier J, Boisrame-Helms J, Brisard L, Lascarrou JB, Ait Hssain A, Anguel N, et al. Enteral versus parenteral early nutrition in ventilated adults with shock: a randomised, controlled, multicentre, open-label, parallel-group study (NUTRIREA-2). Lancet. 2018;391(10116):133-43.

61. Cederholm T, Jensen GL, Correia M, Gonzalez MC, Fukushima R, Higashiguchi T, et al. GLIM criteria for the diagnosis of malnutrition - a consensus report from the global clinical nutrition community. J Cachexia Sarcopenia Muscle. 2019;10(1):207-17.

62. Sheean PM, Peterson SJ, Gomez Perez S, Troy KL, Patel A, Sclamberg JS, et al. The prevalence of sarcopenia in patients with respiratory failure classified as normally nourished using computed tomography and subjective global assessment. JPEN J Parenter Enteral Nutr. 2014;38(7):873-9.

63. Campbell IT, Watt T, Withers D, England R, Sukumar S, Keegan MA, et al. Muscle thickness, measured with ultrasound, may be an indicator of lean tissue wasting in multiple organ failure in the presence of edema. Am J Clin Nutr. 1995;62(3):533-9.

64. Earthman CP. Body composition tools for assessment of adult malnutrition at the bedside: a tutorial on research considerations and clinical applications. JPEN J Parenter Enteral Nutr. 2015;39(7):787-822.

65. Mundi MS, Patel JJ, Martindale R. Body composition technology: implications for the ICU. Nutr Clin Pract. 2019;34(1):48-58.

66. Paris M, Mourtzakis M. Assessment of skeletal muscle mass in critically ill patients: considerations for the utility of computed tomography imaging and ultrasonography. Curr Opin Clin Nutr Metab Care. 2016;19(2):125-30.

67. Wischmeyer PE, Hasselmann M, Kummerlen C, Kozar R, Kutsogiannis DJ, Karvellas CJ, et al. A randomized trial of supplemental parenteral nutrition in underweight and overweight critically ill patients: the TOP-UP pilot trial. Crit Care. 2017:21(1):142.

68. Dickerson RN. Metabolic support challenges with obesity during critical illness. Nutrition. 2019:57:24-31.

69. Frankenfield DC, Ashcraft CM, Galvan DA. Prediction of resting metabolic rate in critically ill patients at the extremes of body mass index. JPEN J Parenter Enteral Nutr. 2013;37(3):361-7.

70. Peterson SJ, Tsai AA, Scala CM, Sowa DC, Sheean PM, Braunschweig CL. Adequacy of oral intake in critically ill patients 1 week after extubation. $J$ Am Diet Assoc. 2010;110(3):427-33.

71. Ridley EJ, Parke RL, Davies AR, Bailey M, Hodgson C, Deane AM, et al. What happens to nutrition intake in the post-intensive care unit hospitalization period? An observational cohort study in critically ill adults. JPEN J Parenter Enteral Nutr. 2019;43(1):88-95.

72. Chapple LS, Deane AM, Heyland DK, Lange K, Kranz AJ, Williams LT, et al. Energy and protein deficits throughout hospitalization in patients admitted with a traumatic brain injury. Clin Nutr. 2016;35(6):1315-22.

73. Merriweather J, Smith P, Walsh T. Nutritional rehabilitation after ICU - does it happen: a qualitative interview and observational study. J Clin Nurs. 2014; 23(5-6):654-62.

74. Stratton RJ, Stubbs RJ, Elia M. Short-term continuous enteral tube feeding schedules did not suppress appetite and food intake in healthy men in a placebo-controlled trial. J Nutr. 2003;133(8):2570-6.

\section{Publisher's Note}

Springer Nature remains neutral with regard to jurisdictional claims in published maps and institutional affiliations. 